\title{
Antenatally Diagnosed Suprarenal Cystic Teratoma
}

\section{${ }^{1}$ Rajan Garg, ${ }^{2}$ Ankur Mandelia, ${ }^{3}$ Sandeep Agarwala, ${ }^{4}$ Veereshwar Bhatnagar, ${ }^{5} \mathrm{MK}$ Singh, ${ }^{6}$ Manisha Jana}

\section{ABSTRACT}

A two months old female child presented to us with an antenatal diagnosis of left suprarenal mass. Laparotomy revealed a large cystic mass in the left suprarenal location which was completely excised. The histological diagnosis was a mature, cystic teratoma. Although, the diagnosis of adrenal teratoma is rare, it should be considered in the differential diagnosis of antenatally diagnosed suprarenal lesions.

Keywords: Adrenal teratoma, Antenatal diagnosis, Suprarenal teratoma.

How to cite this article: Garg R, Mandelia A, Agarwala S, Bhatnagar V, Singh MK, Jana M. Antenatally Diagnosed Suprarenal Cystic Teratoma. World J Endoc Surg 2015;7(2):44-46.

\section{Source of support: Nil}

Conflict of interest: None

\section{INTRODUCTION}

Suprarenal tumors diagnosed antenatally or in the early neonatal period are always diagnostic dilemmas. Various authors have reported the suprarenal mass to be neuroblastoma, adrenal hemorrhage, extrapulmonary sequestration, bronchogenic cyst, renal dysplasia or adrenal teratoma. ${ }^{1-5}$ Antenatally diagnosed suprarenal tumors are rare and their management guidelines have not been fully defined. Antenatal diagnosis of these tumors is increasing because of extensive use of prenatal ultrasound. We report a case of cystic adrenal tumor diagnosed antenatally.

\section{CASE REPORT}

A two months old female child presented to us with an antenatally diagnosed cystic lesion in the left suprarenal

\footnotetext{
${ }^{1,2}$ Senior Resident, ${ }^{3-5}$ Professor, ${ }^{6}$ Assistant Professor

${ }^{1-4}$ Department of Pediatric Surgery, All India Institute of Medical Sciences, New Delhi, India

${ }^{5}$ Department of Pathology, All India Institute of Medical Sciences New Delhi, India

${ }^{6}$ Department of Radiodiagnosis, All India Institute of Medical Sciences, New Delhi, India
}

Corresponding Author: Veereshwar Bhatnagar, Professor Department of Pediatric Surgery, All India Institute of Medical Sciences, New Delhi, India, Phone: +911126593309, e-mail: veereshwarb@hotmail.com fossa. The mass was detected on a routine antenatal ultrasound scan at 32 weeks gestation. Perinatal period was uneventful. The child was born by spontaneous vaginal delivery at term. Postnatally, the patient was asymptomatic and blood pressure was in the normal range for age. Abdominal examination revealed a palpable lump in the left flank, which was firm, fixed and nontender. Ultrasound scan revealed a $72 \times 60 \mathrm{~mm}$ cystic lesion in the left suprarenal fossa. Multiphase CT scan of the abdomen revealed a complex multiloculated cystic lesion in the left suprarenal fossa, measuring $76 \times 70 \times 65 \mathrm{~mm}$ in size and having internal septations (Figs 1A and B). Left kidney was displaced inferiorly. Aorta and blood vessels were not involved by the tumor. There was no
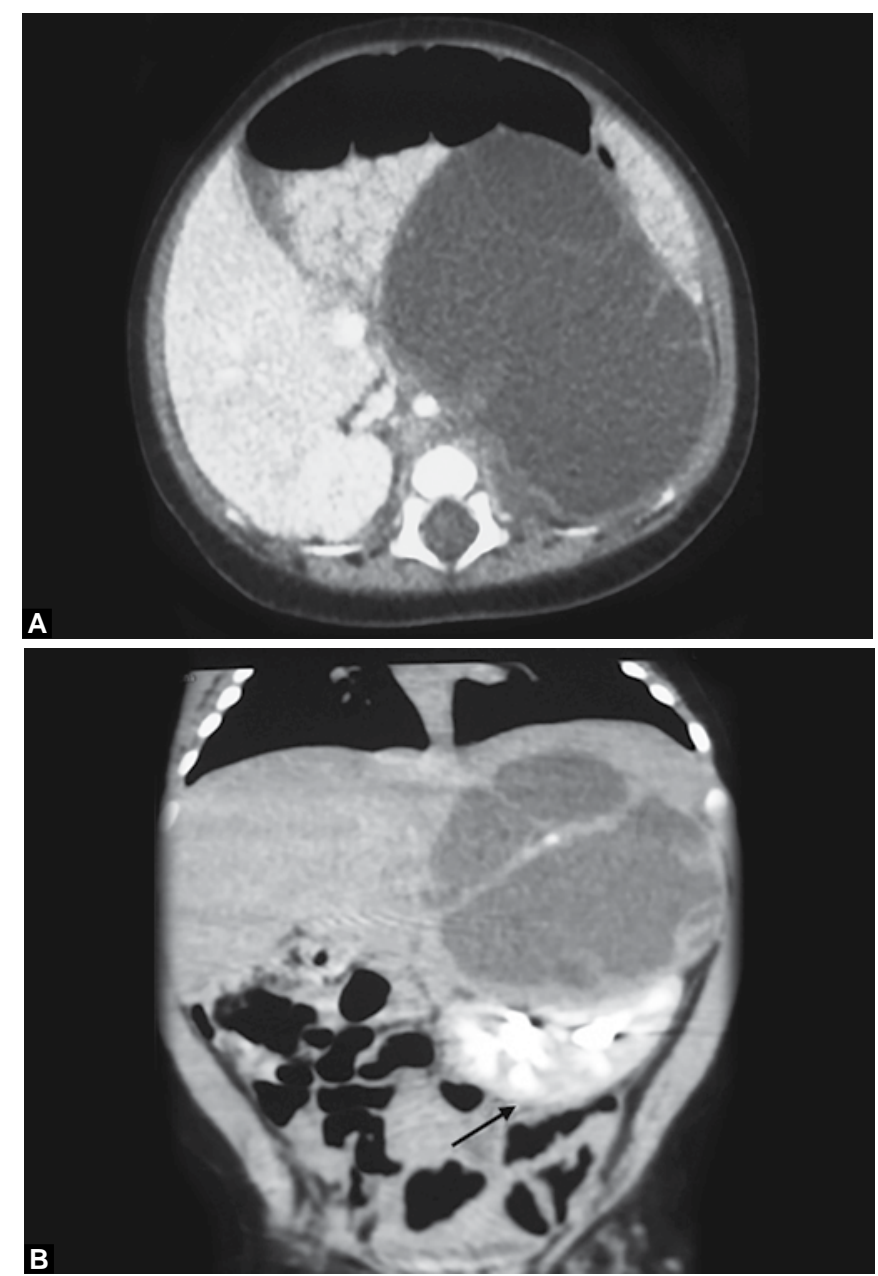

Figs $1 \mathrm{~A}$ and $\mathrm{B}$ : Multiphase CT scan of the abdomen: $(\mathrm{A})$ axial and (B) coronal section showing a complex multiloculated cystic lesion in the left suprarenal fossa, measuring $76 \times 70 \times 65 \mathrm{~mm}$ in size and having internal septations. Left kidney was displaced inferiorly (arrow) 
evidence of fat or calcification. On the basis of imaging, a diagnosis of cystic adrenal neuroblastoma was made. Fine needle aspiration cytology from the solid part of the lesion was inconclusive. Twenty-four hours urinary vanillylmandelic acid (VMA) and homovanillic acid (HVA) levels were within normal range.

As the size of the lesion was progressively increasing on serial imaging, excision of the tumor was planned. Laparotomy revealed a large tense cystic lesion in the left suprarenal location. Left adrenal gland could not be seen separately from the mass. Splenic vein and pancreas were splayed over the mass superiorly. The mass was densely adherent to the left kidney. The tumor was excised completely with no gross residue.

Histopathology revealed features of mature cystic teratoma. Macroscopically the tumor was well encapsulated, cystic and contained gray white cheesy material. Microscopically the tumor comprised of mature tissue elements derived from of all three germ cell layers, such as skin adnexal structures, respiratory epithelium, glial tissue, adipose tissue and cavernous blood vessels (Fig. 2A). Immature elements were not identified. Compressed normal adrenal tissue was identified at the periphery (Fig. 2B). Serum alpha fetoprotein level was done postoperatively and was normal for age. Patient is asymptomatic at 6 months follow-up with no evidence of recurrent/residual tumor.

\section{DISCUSSION}

Prenatal detection of fetal anomalies and masses has become increasingly common with the growing use of ultrasonography. Neuroblastoma is the most common suprarenal mass detected during prenatal ultrasonography, but suprarenal masses also can represent adrenal hemorrhage, extrapulmonary sequestration, a bronchogenic cyst, or renal dysplasia. ${ }^{1,2}$ Precise diagnosis of these antenatally detected lesions is not possible in all patients. Radiologic diagnosis of some tumors may not be possible and FNAC does not yield good results for cystic lesions. Deeg et al described features on imaging that have to be taken into account for diagnosis, i.e. the size of the mass, presence of calcification, echogenicity (cystic, solid or heterogenous), shape (round or triangular) and the characteristics of the connection with adrenal gland and the kidney. ${ }^{6}$ Our patient had a suprarenal cystic tumor without any evidence of calcification.

Criteria for surgical intervention of antenatally detected suprarenal tumors have not been laid down. This has not been possible because of the low incidence of these tumors. In the last decade there has been a sudden rise in the number of antenatal detection of such tumors.

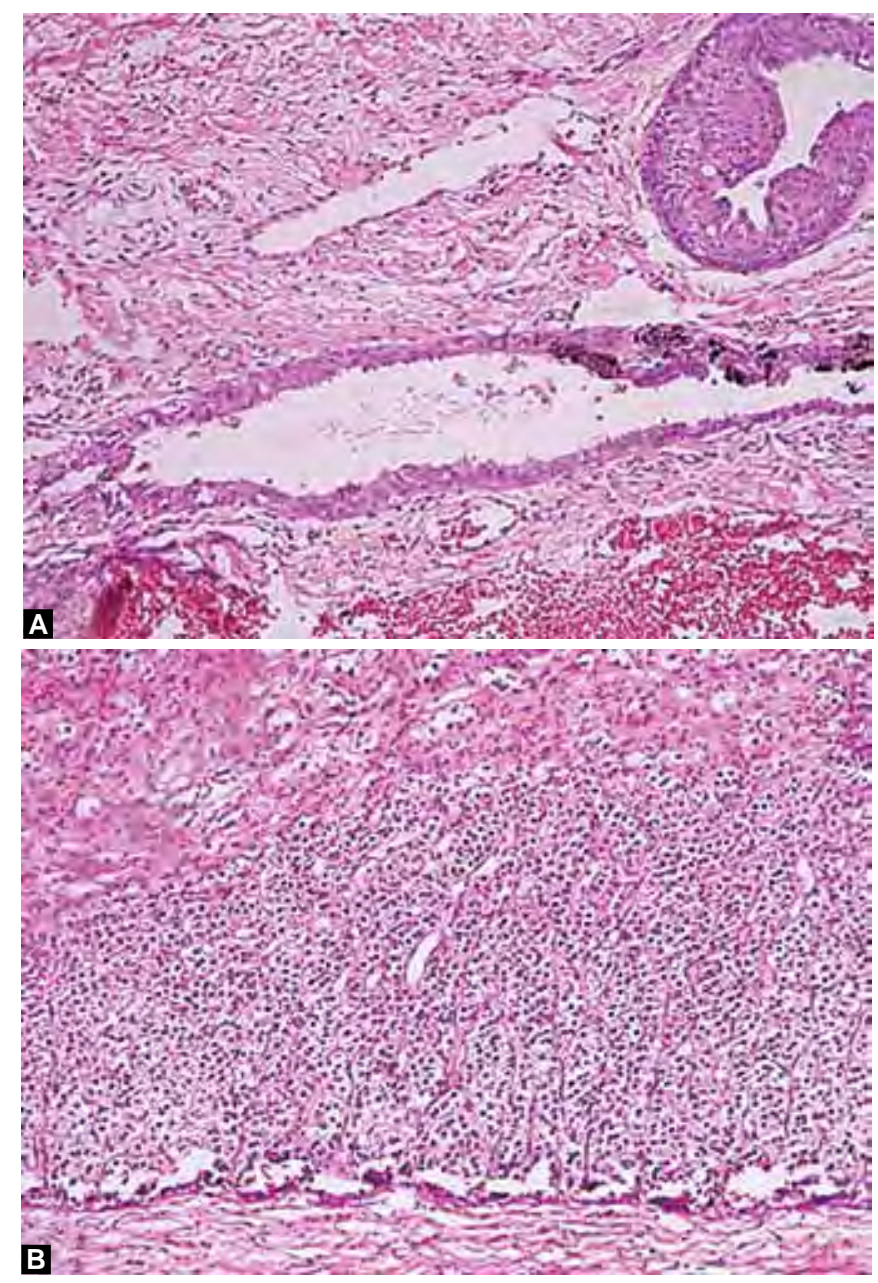

Figs 2A and B: (A) H\&E staining $(\times 10)$ showing various tissue components of mature cystic teratoma in the form of skin adnexal structure, respiratory epithelium, cavernous blood vessels and glial tissue; $(B)$ H\&E staining $(\times 10)$ showing compressed adrenal tissue at the periphery

As per the currently available literature, indications of surgical resection have been defined variably as:

- Confirmed diagnosis of neuroblastoma.

- Size of the lesion ( $\geq 16 \mathrm{ml}$ if it is solid and $\geq 65 \mathrm{ml}$ if at least $25 \%$ cystic).

- Persistence of suprarenal mass 6 months after birth.

- Increasing size of the lesion. ${ }^{1,7}$ In our patient, increasing size of the lesion was the indication for excision.

Antenatal diagnosis of adrenal teratoma has been reported only once previously. ${ }^{2}$ Adrenal teratoma in the pediatric age group has been reported previously in a neonate by James et $\mathrm{al}^{3}$ and in an 8-year-old girl by Khong et al. ${ }^{8}$ In all these cases, complete excision was the treatment of choice.

\section{CONCLUSION}

Though the diagnosis of adrenal teratoma is rare, it should be considered in the differential diagnosis of antenatally diagnosed suprarenal lesions. Complete surgical excision of the teratoma is advised. 


\section{REFERENCES}

1. Sauvat F, Sarnacki S, Brisse H, et al. Outcome of suprarenal localized masses diagnosed during the prenatal period: a retros-pective multicenter study. Cancer 2002;94(9):2474-2480.

2. Oguzkurt P, Ince E, Temiz A, Demir S, Akabolat F, Hicsonmez A, et al. Prenatal diagnosis of a mass in the adrenal region that proved to be a teratoma. J Pediatr Hematol Oncol 2009;31(5):350-351.

3. James J, Dhillon GS, Blewett CJ, Halidorsson A, Cecalupo AJ. A large adrenal teratoma in a neonate. Am Surg 2009;75(4): 347-349.

4. Yao W, Li K, Xiao X, Zheng S, Chen L. Neonatal suprarenal mass: differential diagnosis and treatment. J Cancer Res Clin Oncol 2013;139(2):281-286.
5. Singal AK, Agarwala S, Seth T, Gupta AK, Mitra DK. Intraabdominal extralobar pulmonary sequestration presenting antenatally as a suprarenal mass. Indian J Pediatr 2004;71(12): 1137-1139.

6. Deeg KH, Bettendorf U, Hofmann V. Differential diagnosis of neonatal adrenal hemorrhage and congenital neuroblastoma by color coded Doppler sonography and power Doppler sonography. Eur J Pediatr 1998;157(4):294-297.

7. Masiakos PT1, Gerstle JT, Cheang T, Viero S, Kim PC, Wales P. Is surgery necessary for incidentally discovered adrenal masses in children? J Pediatr Surg 2004;39(5):754-758.

8. Khong PL, Lam KY, Ooi CGC, Liu MJ, Metreweli C. Mature teratoma of the adrenal gland: imaging features. Abdom Imaging 2002;27(3):347-350. 